\title{
In situ associations between marine photosynthetic picoeukaryotes and potential parasites - a role for fungi?
}

\author{
Cécile Lepère, ${ }^{1,2,3 *}$ Martin Ostrowski, ${ }^{4}$ \\ Manuela Hartmann, ${ }^{5}$ Mikhail V. Zubkov ${ }^{5}$ and \\ David J. Scanlan ${ }^{1 * *}$ \\ ${ }^{1}$ School of Life Sciences, University of Warwick, \\ Coventry CV4 7AL, UK. \\ ${ }^{2}$ Université Clermont Auvergne, Université Blaise \\ Pascal, Laboratoire 'Microorganismes : Génome et \\ Environnement', BP 10448, Clermont-Ferrand F-63000, \\ France. \\ ${ }^{3}$ CNRS, UMR 6023, LMGE, Aubière F-63171, France. \\ ${ }^{4}$ Department of Chemistry and Biomolecular Sciences, \\ Macquarie University, North Ryde, NSW 2109, \\ Australia. \\ ${ }^{5}$ National Oceanography Centre, Hampshire SO14 3ZH, \\ UK.
}

\section{Summary}

Photosynthetic picoeukaryotes (PPEs) are important components of the marine picophytoplankton community playing a critical role in $\mathrm{CO}_{2}$ fixation but also as bacterivores, particularly in the oligotrophic gyres. Despite an increased interest in these organisms and an improved understanding of the genetic diversity of this group, we still know little of the environmental factors controlling the abundance of these organisms. Here, we investigated the quantitative importance of eukaryotic parasites in the free-living fraction as well as in associations with PPEs along a transect in the South Atlantic. Using tyramide signal amplification-fluorescence in situ hybridization (TSAFISH), we provide quantitative evidence of the occurrence of free-living fungi in open ocean marine systems, while the Perkinsozoa and Syndiniales parasites were not abundant in these waters. Using flow cytometric cell sorting of different PPE populations followed by a dual-labelled TSA-FISH approach, we also demonstrate fungal associations, potentially parasitic, occurring with both pico-Prymnesiophyceae and pico-Chrysophyceae. These data highlight the

Received 6 August, 2015; revised 23 September, 2015; accepted 25 September, 2015. For correspondence. *E-mail cecile.lepere@ univbpclermont.fr; Tel. 334734051 56; Fax 334734076 70. **E-mail d.j.scanlan@warwick.ac.uk; Tel. 442476 528363; Fax +44 2476 523701. necessity for further work investigating the specific role of marine fungi as parasites of phytoplankton to improve understanding of carbon flow in marine ecosystems.

\section{Introduction}

Photosynthetic picoeukaryotes (PPEs), herein defined as cells $<5 \mu \mathrm{m}$ in diameter, are gaining recognition as significant contributors to $\mathrm{CO}_{2}$ fixation in many marine ecosystems (Cuvelier et al., 2010; Jardillier et al., 2010). While long considered as obligate autotrophs, PPEs are now known to include active bacterivores, i.e. they exhibit mixotrophic behaviour (Hartmann et al., 2012; 2013; Unrein et al., 2014). Hence, these organisms are not only key $\mathrm{CO}_{2}$ fixers but also play a role in controlling bacterioplankton abundance, acting as producers of organic matter and predators at the same time. Interest in these organisms has thus increased dramatically in recent years, and we now have a relatively good knowledge of their molecular diversity, largely through surveys of nuclear and plastid-encoded small subunit rRNA genes (e.g. Vaulot et al., 2008; Kirkham et al., 2013). In contrast, factors controlling the abundance of PPEs remain poorly understood. Recent ship-board nutrient addition experiments suggest that, at least over the short term (10-11 h), nutrient availability does not limit $\mathrm{CO}_{2}$ fixation by these organisms (Grob et al., 2015), suggesting top-down regulation the most likely controlling factor of open ocean PPE $\mathrm{CO}_{2}$ fixation. Here, we investigated the impact of eukaryotic parasitism on PPEs, which remains largely unexplored in ocean ecosystems.

Eukaryotic parasites are characterized by complex life cycles. They can include developmental stages comprising free-living zoospores 2-6 $\mu \mathrm{m}$ in size that are well represented in molecular studies (Chambouvet et al., 2008, 2014; Guillou et al., 2008). As a result they can infect hosts belonging to various trophic levels (Marcogliese and Cone, 1997). For a long time they have been neglected in mathematical models of aquatic trophic networks (Lafferty et al., 2008). However, their introduction into such models can have important qualitative and quantitative impacts on ecosystem functioning, e.g. by extending the length of food chains and/or modulating the transfer of carbon (Niquil et al., 2011). 
In oceanic environments eukaryotic parasites are mainly representatives of the 'superphylum' Alveolata - a polyphyletic group including ciliates, Apicomplexa, Perkinsozoa and Dinoflagellata (Leander and Keeling, 2003; Chambouvet et al., 2008, 2014; Guillou et al., 2008; Gachon et al., 2010). Many Fungi, especially those belonging to Chytridiomycota, are also known to be parasitic in a wide range of habitats (e.g. see Sime-Ngando et al., 2011). However, very few fungal lineages have been detected or isolated from oceanic environments (Massana and Pedrós-Alió, 2008), perhaps due to the limited number of geographic regions that have been analysed so far. Fungal diversity has been investigated by both conventional culture-dependent methods (Burgaud et al., 2009; Le Calvez et al., 2009; Jebaraj et al., 2010) and culture-independent methods (Nagahama et al., 2001; Bass et al., 2007; Lopez-Garcia et al., 2007; Jebaraj et al., 2010; Nagano et al., 2010; Sauvadet et al., 2010). Deep-sea environments, including hydrothermal vents, are the best studied in terms of fungal composition (for a review see Nagano and Nagahama, 2012). Fungi reported from these environments mostly belong to the phylum Ascomycota. However, Chytridiomycota have also been detected as one of the major fungal components in several deep-sea environments, such as hydrothermal vents and methane cold seeps, but only by culture-independent methods (Nagano and Nagahama, 2012). In contrast, very few species have been detected in surface marine waters using both culture- and cultureindependent approaches (Massana and Pedrós-Alió, 2008; Gleason and Marano, 2011; Richards et al., 2012; Lepelletier et al., 2014). Therefore, culture-independent molecular probing of potentially infected organisms could reveal important new information about interactions with marine fungi.

Here, we employed a sensitive dual-label (parasitehost) tyramide signal amplification-fluorescence in situ hybridization (TSA-FISH) analysis to begin to evaluate the potential impact of eukaryotic parasitism by members of the Syndiniales, Perkinsozoa and a wide range of Fungi, including Chytridiales (i.e. the largest group of the truefungal division of Chytridiomycota) on PPEs. Samples used in this study were collected along a transect in the Atlantic Ocean from 13 October to 1 December 2009 during the AMT19 cruise (Fig. 1) aboard the Royal Research Ship James Cook. Ten stations encompassing the southern subtropical gyre (SG) and the southern temperate (ST) region of the Atlantic Ocean were sampled from the surface mixed layer. Filtered samples were analysed to evaluate the abundance and distribution of freeliving members of the Syndiniales, Perkinsozoa and Fungi along AMT19. We also combined flow cytometric cell sorting and dual-label TSA-FISH to determine the interactions between PPEs and potential parasites for two differ- ent PPE size fractions that are easily distinguishable populations on flow cytograms: small, plastidic eukaryotes (Plast-S, $2 \pm 0.1 \mu \mathrm{m}$ in size) and large, plastidic eukaryotes (Plast-L, $3.1 \pm 0.3 \mu \mathrm{m}$ in size). For more details on the materials and methods, please refer to Appendix S1.

\section{Results and discussion}

\section{PPE composition along AMT19}

To determine which photosynthetic classes were potentially susceptible to parasitism, we first assessed the composition of the Plast-S and Plast-L populations along AMT19. The contribution of different classes to the total eukaryotic community $(<5 \mu \mathrm{m})$ is expressed as a percentage of all positively hybridized eukaryotic cells targeted by the probe EUK1209 (Giovannoni et al., 1988). At all stations, the Plast-S fraction was dominated by Pelagophyceae $(30 \pm 11 \%)$ and Chrysophyceae $(20 \% \pm 14)$, whereas Prymnesiophyceae were the principal component of the Plast-L cells (48 $\pm 18 \%)$ (Table S1). Cryptophyceae were detected at some stations, but where detected, represented only $2 \pm 1 \%$ of the total eukaryote population in both fractions (Table S1). The composition of these PPE size classes is similar to those obtained previously in Atlantic waters (Jardillier et al., 2010; Grob et al., 2011). At most of the stations the three classes, Prymnesiophyceae, Chrysophyceae and Pelagophyceae, encompassed the majority of PPEs. However, for some stations (i.e. JC039056; JC03970), the percentage of PPEs targeted by these FISH probes was rather low, suggesting other PPE classes, perhaps with more sporadic distributions, dominate in such locations. Indeed, previous molecular characterization found that, for example some Prasinophyceae clades (e.g. 16S Clades VI and VIII), can constitute a large part of the PPE community in some oceanic regions (Kirkham et al., 2013).

\section{Parasite abundance and distribution along AMT19}

Sequences affiliated to Syndiniales have been regularly observed in 18S rRNA gene libraries from marine ecosystems (Guillou et al., 2008). However, their quantitative distribution has rarely been studied in oceanic waters (Siano et al., 2011). The abundance of the free living stage of Syndiniales (dinospores, 3-7 $\mu \mathrm{m}$ diameter, Fig. 2A) assessed using the general Syndiniales group II probe (ALV01) was highly variable along the AMT19 transect, although generally cell numbers were low. No Syndiniales dinospores were detected at six stations (Table 1), principally in the SG, whereas in ST areas they reached a maximum concentration at station JC03972 ( 800 cells $\mathrm{ml}^{-1}$ ) and contributed up to $26 \%$ of total 


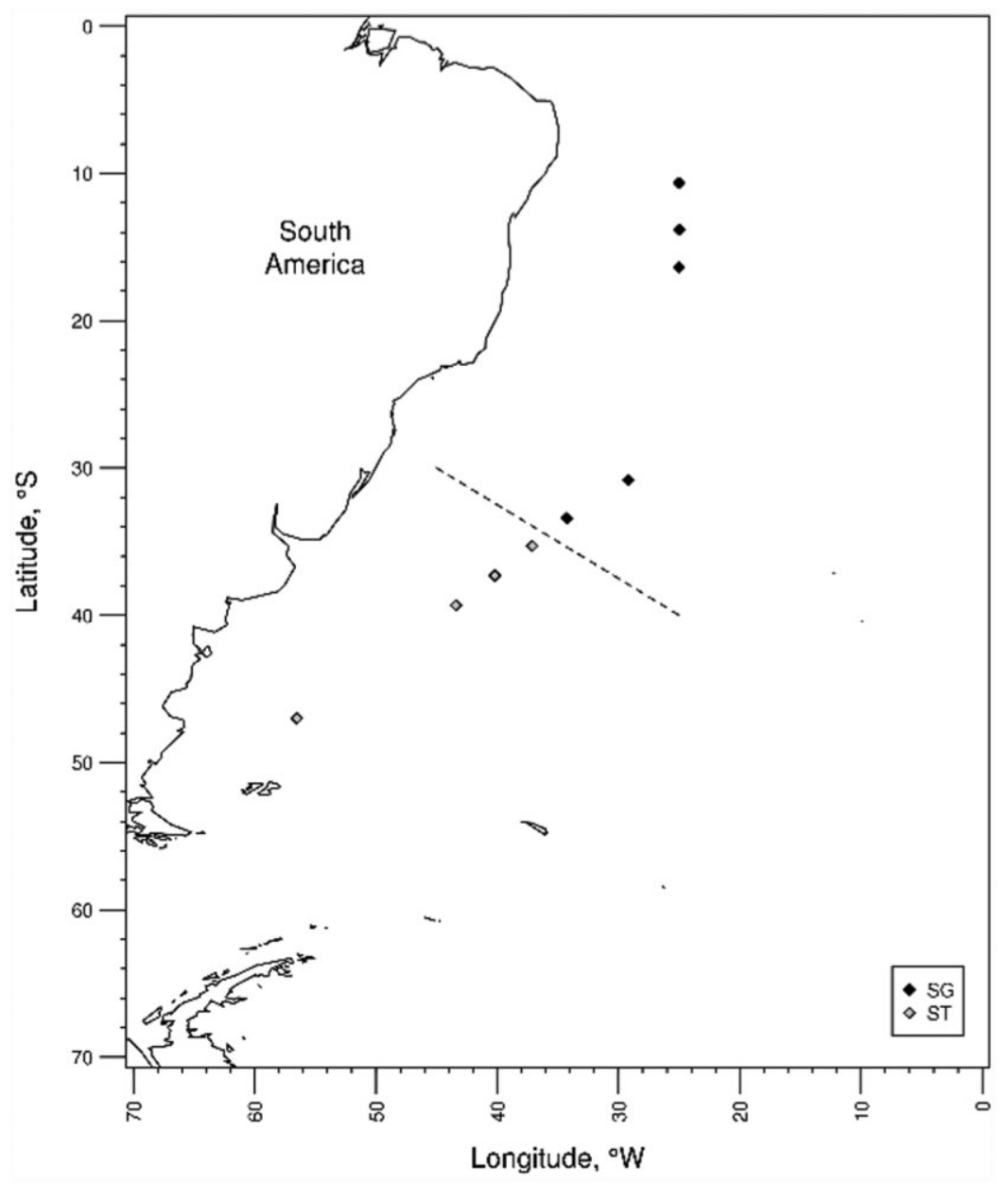

Fig. 1. A schematic map of the South Atlantic Ocean showing the area sampled along AMT19 in 2009. ST: southern temperate region; SG: southern subtropical gyre; dotted line represents the separation between ST and SG.

Table 1. The percentage contribution of Syndiniales and Fungi, targeted by the ALVO1, MY1574 and Chyt1061 probes, respectively, to the total eukaryotic community $(<5 \mu \mathrm{m})$.

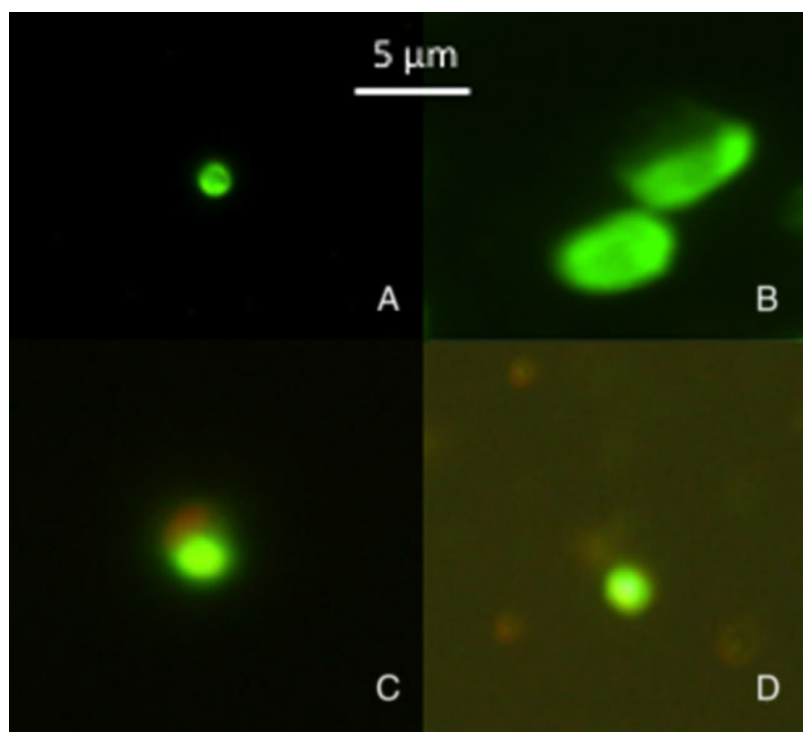

Fig. 2. Epifluorescence micrographs of $(A)$ free-living Syndiniales (targeted by the ALV01 probe), (B) Perkinsozoa (targeted by the PERKIN-01 probe), and (C, D) fungi (targeted by probes MY1574, and Chyt1061) (the green colour shows the positive signal of the horseradish peroxidase (HRP)-labelled probes).

C 2015 Society for Applied Microbiology and John Wiley \& Sons Ltd, Environmental Microbiology Reports 
eukaryote cells (<5 $4 \mathrm{~m}$; targeted by the probe EUK1209). However, the total abundance of Syndiniales may be underestimated because of the specificity of the ALV01 probe, which targets only 33 of the 44 described clades. Unfortunately, oligonucleotide probes for FISH analyses could not be designed to cover the entire genetic diversity of marine alveolates group 2 (MALV II, Siano et al., 2011). Nonetheless, our FISH data are consistent with Syndiniales dinospores being more abundant in coastal waters compared with open ocean sites, especially when considering oligotrophic systems (Chambouvet et al., 2008; Guillou et al., 2008; Siano et al., 2011). Indeed, these latter authors found a positive correlation between zoospore occurrence and higher nutrient concentrations.

The phylum Perkinsozoa is part of the Alveolata 'superphylum' and comprises a diverse group of aquatic parasites infecting a wide range of species, such as molluscs, amphibians and phytoplankton (Brate et al., 2010; Lepelletier et al., 2014). However, FISH analysis using the PERKIN_01 and PERKIN_02 probes gave no positive signals, except for stations JC03970 (1-2 cells $\left.\mathrm{ml}^{-1}\right)$ and JC03972 (3-4 cells $\mathrm{ml}^{-1}$ ) (Fig. 2B). This is consistent with Perkinsozoa being largely absent from the water column but rather being preferentially found in sediments (Chambouvet et al., 2014).

Recent environmental surveys of lacustrine microbial eukaryotes have revealed a wide species diversity and major role of fungal parasites in these systems, consisting primarily of chytrids (Chytridiomycota). In contrast, $18 \mathrm{~S}$ rRNA gene surveys focusing on the small eukaryotic fraction $(<5 \mu \mathrm{m})$ in surface ocean waters have shown $<1 \%$ of the sequences to be affiliated with fungi (Massana and Pedrós-Alió, 2008). However, whether this low abundance of fungal sequences is real or due to copy number bias when using the 18S rRNA gene (Zhu et al., 2005) is unclear. To potentially get around the copy number problem, herein we assessed the distribution and abundance of free living fungal stages along AMT19 using three FISH probes targeting (i) all divisions of the Eumycota (MY1574; Baschien et al., 2008), (ii) fungal species of the order Chytridiales (Chyt1061; Jobard et al., 2010), and (iii) a subsection of environmental fungal sequences branching within the Cryptomycota clade, which forms one of the deepest branches within the fungi (LKM11_01; Mangot et al., 2009). Members of Chytridiales and Cryptomycota can be parasites of phytoplankton in freshwater ecosystems (Jones et al., 2011; Sime-Ngando et al., 2011).

Free-living stages of fungi (mostly zoospores) were observed at all stations with probe MY1574, representing on average $9.3 \%$ of the total eukaryote community (Table 1 and Fig. 2C). The maximum abundance of Eumycota (14\% of all eukaryote cells targeted by the probe EUK1209) was recorded at station JC03974 in the
ST region. Chytridiales (Chyt1061 probe) were less abundant, representing on average $3.5 \%$ of the total eukaryote community and were absent from surface waters at three stations (Table 1). The LKM11-01 probe gave no positive signals at station sampled along AMT19, suggesting members of the Cryptomycota are not abundant in ocean surface waters (Jones et al., 2011), although environmental sequences corresponding to this group have been retrieved from deep-sea ecosystems, ocean sediments and freshwater lakes (Lepère et al., 2008; Jones et al., 2011; Nagano and Nagahama, 2012).

\section{Associations between PPEs and potential parasites}

Using dual labelling TSA-FISH on sorted Plast-S and Plast-L cells, no association was detected between Syndiniales dinospores and PPEs. This observation is consistent with their known parasitism of larger cell types, e.g. dinoflagellates (Siano et al., 2011). An increase in abundance of larger eukaryotic cells may be the reason for the comparatively high Syndiniales cell counts at station JC03972, although unfortunately we did not perform dinoflagellate cell counts here.

Studies of fungal pathogens of marine algae have mostly focused on macroalgae (Kohlmeyer and Kohlmeyer, 1979; Küpper et al., 2006) and tend to rely on cultivation-based methods. In this study, dual-labelled TSA-FISH combined with wheat germ agglutinin (WGA) chitin staining allowed us to detect associations between fungi and PPEs. The fungal structures that were identified correspond to the chitin positive sporangia life stage. Sporangia, which are larger than zoospores, appear attached to the surface of their algal hosts (Figs 3 and 4). The use of oligonucleotide probes that target rRNA allows for visualization of active cells, which helps to reject the hypothesis of saprotrophic nutrition by the attached fungi.

No fungal associations were observed for any PPE class within the Plast-S population. However, dual TSA-FISH demonstrated fungi in association with Prymnesiophyceae and Chrysophyceae within Plast-L populations from several stations along the transect (Figs 3 and 4, Table 2). We would argue here that the significant difference $(P<0.05)$ in associations between Plast-S and Plast- $L$ populations is not due to sampling and sorting issues since the same method was used. Where positive signals were detected, on average $3 \pm 0.6 \%$ of Chrysophyceae cells were associated with fungi (detected by probes MY1574 and Chyt1061; Table 2, Fig. 4). In contrast, an average of $6.4 \pm 0.9 \%$ Plast-L Prymnesiophyceae cells were identified with attached fungal structures detected by the Eumycota probe MY1574 and 3.5\% (on average) with the Chytrid probe Chyt1061. These associations were observed at stations all along the AMT19 transect studied here, includ- 


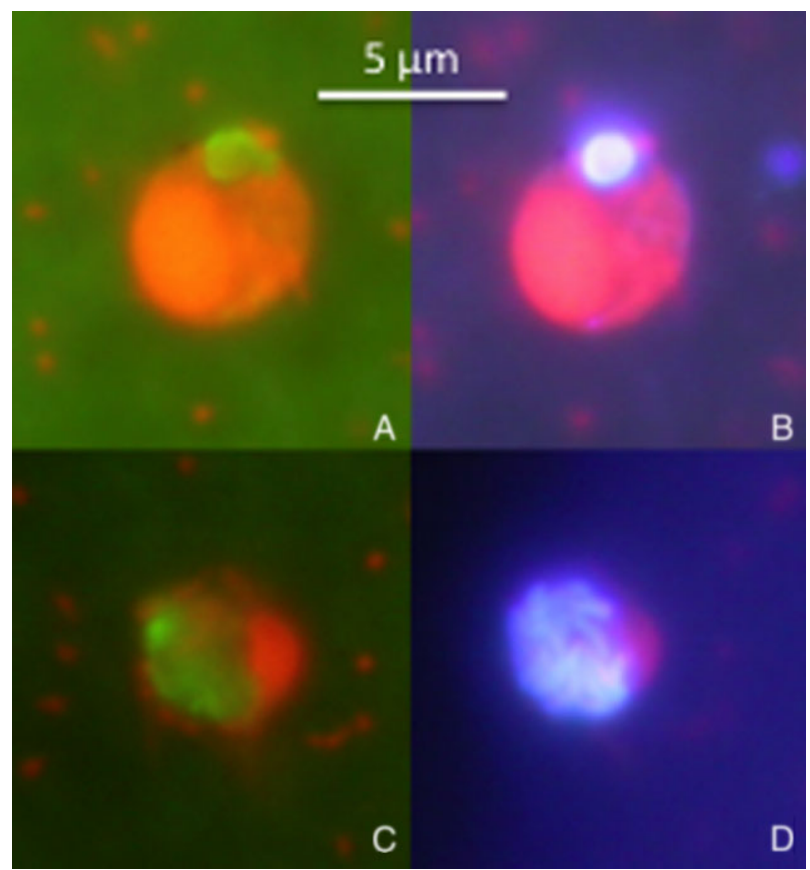

Fig. 3. Epifluorescence micrographs of the potentially different stages of fungal infection of Prymnesiophyceae cells. The green colour shows the positive signal of the horseradish peroxidase (HRP)-labelled probe MY1574 (A, C), while the blue colour is wheat germ agglutinin binding of chitin cell walls (B, D), and the red colour constitutes the positive signal of the PRYM02 probe after TSA-FISH.

ing both ST and SG regions (Table 2), the numbers corresponding fairly well to observed maximum abundance of Prymnesiophyceae in the flow sorted Plast-L population (Table S1). Moreover, we were able to see putative different stages of a fungal infection, highlighted by positive signals with the MY1574 probe combined with WGA staining detecting the presence of fungal chitin (Fig. 3).

\section{Conclusions}

This work suggests the quantitative importance of fungi in open ocean pelagic marine systems. Our direct microscopy observations complement phylogenetic data (for a review, see Richards et al., 2012) which suggested that marine fungi are more abundant and taxonomically diverse than previously thought. Thus, they are known to include a number of novel groups, the majority of which branch below the Dikarya radiation, close to the chytrid branches (Le Calvez et al., 2009; Richards et al., 2012), and are suspected to be parasitic.

Indeed, here, for the first time, we demonstrate potentially parasitic fungal associations with picophytoplankton, particularly members of the Prymnesiophyceae, one of the most abundant members of the PPE community globally (Liu et al., 2009; Kirkham et al., 2013). Further investigation of the diversity and specific roles of marine fungi is therefore warranted, particularly to better understand carbon flow in pelagic ecosystems. Besides viral and grazing pressure, our data suggest that picophytoplankton may be subjected to parasitism across vast tracts of the global ocean. We propose that future investigation of eukaryotic parasitism will provide important new insights essential for measuring and modelling microbial food webs and biogeochemical cycles.

\section{Acknowledgements}

The authors would like to thank the Captain and crew aboard the RRS James Cook during AMT19. We thank Sophie Mazard for her helpful comments on the manuscript. This study was supported by the UK Natural Environment Research Council through Research Grants NE/F004249/1 and NE/G005125/1. C.L. was supported by the FP7-IEF Marie Curie Program. This is Atlantic Meridional Transect Publication No. 203.

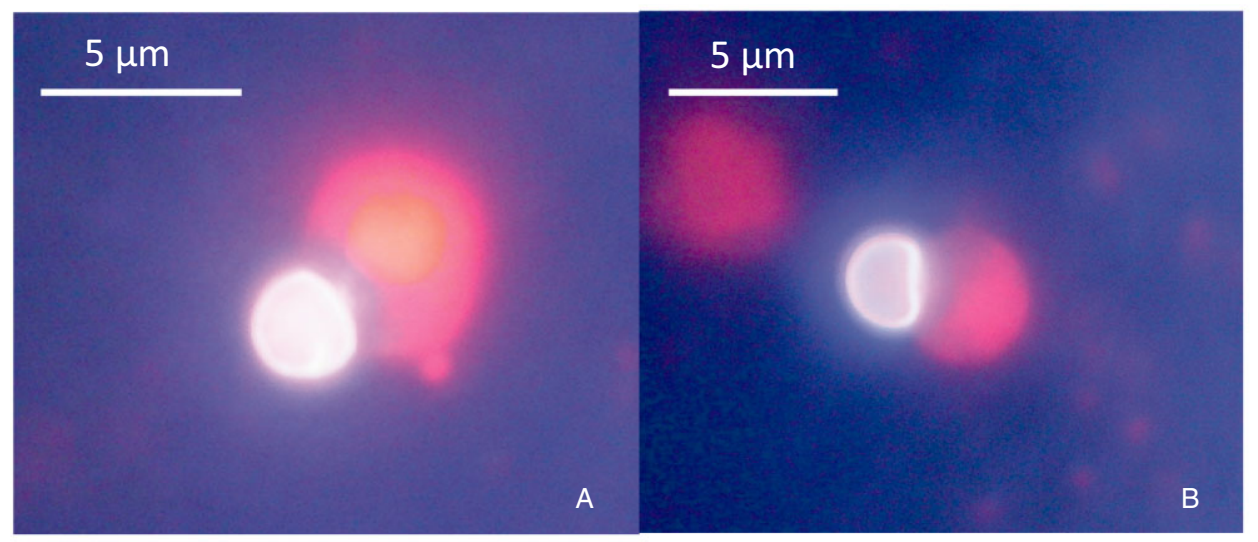

Fig. 4. Epifluorescence micrographs of (A) a Prymnesiophyceae (PRYM02 probe, red) and (B) a Chrysophyceae (CHRYSO1037 probe, red) in association with chitin structures (stained with wheat germ agglutinin, in blue/white). 
Table 2. The percentage association between PPEs and fungi along AMT19.

\begin{tabular}{|c|c|c|c|c|c|c|}
\hline & \multirow[b]{3}{*}{ Station } & \multirow[b]{3}{*}{$\begin{array}{l}\text { Depth } \\
\text { (m) }\end{array}$} & \multicolumn{4}{|c|}{ Plast-L } \\
\hline & & & $\begin{array}{l}\text { \% Association with } \\
\text { Prymnesiophyceae } \\
\text { (PRYM02) }\end{array}$ & $\begin{array}{l}\text { \% Association with } \\
\text { Chrysophyceae } \\
\text { (CHRYSO1037) }\end{array}$ & $\begin{array}{l}\text { \% Association with } \\
\text { Prymnesiophyceae } \\
\text { (PRYM02) }\end{array}$ & $\begin{array}{l}\text { \% Association with } \\
\text { Chrysophyceae } \\
\text { (CHRYSO1037) }\end{array}$ \\
\hline & & & \multicolumn{2}{|c|}{$\begin{array}{l}\text { General fungi } \\
\text { probe (MY1574) }\end{array}$} & \multicolumn{2}{|c|}{$\begin{array}{c}\text { Chytridiales } \\
\text { probe (Chyt1061) }\end{array}$} \\
\hline$S G$ & JC039053 & 5 & 7 & 5 & 5 & 1 \\
\hline SG & JC039053 & 25 & 5 & 2 & 0 & 0 \\
\hline$S G$ & JC039055 & 5 & 9 & 0 & 3 & 0 \\
\hline$S G$ & JC039056 & 5 & 0 & 0 & 5 & 2 \\
\hline SG & JC03967 & 5 & 0 & 0 & 0 & 0 \\
\hline SG & JC03967 & 25 & 0 & 1 & 0 & 0 \\
\hline SG & JC03969 & 5 & 6 & 0 & 3 & 0 \\
\hline SG & JC03970 & 88 & 0 & 0 & 0 & 0 \\
\hline ST & JC03971 & 5 & 4 & 6 & 3 & 3 \\
\hline ST & JC03972 & 5 & 0 & 0 & 0 & 0 \\
\hline ST & JC03974 & 10 & 12 & 4 & 2 & 0 \\
\hline \multirow[t]{2}{*}{ ST } & JC039 & 5 & 2 & 0 & 0 & 0 \\
\hline & Mean & & 4 & 1.5 & 2 & 0.5 \\
\hline
\end{tabular}

\section{References}

Baschien, C., Manz, W., Neu, T.R., Marvanova, L., and Scewzyk, U. (2008) In situ detection of freshwater fungi in an alpine stream by new taxon-specific fluorescence in situ hybridization probes. Appl Environ Microbiol 74: 64276436.

Bass, D., Howe, A., Brown, N., Barton, H., Demidova, M., and Michelle, H. (2007) Yeast forms dominate fungal diversity in the deep oceans. Proc Biol Sci 274: 3069-3077.

Brate, J., Logares, R., Berney, C., Ree, D.K., Klaveness, D., Jakobsen, K.S. et al (2010) Freshwater Perkinsea and marine-freshwater colonizations revealed by pyrosequencing and phylogeny of environmental rDNA. ISME J 4: 1144-1153

Burgaud, G., Le Calvez, T., Arzur, D., Vandenkoornhuyse, P., and Barbier, G. (2009) Diversity of culturable marine filamentous fungi from deep-sea hydrothermal vents. Environ Microbiol 11: 1588-1600.

Chambouvet, A., Morin, P., Marie, D., and Guillou, L. (2008) Control of toxic marine dinoflagellate blooms by serial parasitic killers. Science 322: 1254-1257.

Chambouvet, A., Berney, C., Romac, S., Audic, S., Maguire, F., de Vargas, C., and Richards, T.A. (2014) Diverse molecular signatures for ribosomally 'active' Perkinsea in marine sediments. BMC Microbiol. doi: 10.1186/14712180-14-110.

Cuvelier, M.L., Allen, A.E., Monier, A., McCrow, J.P., Messié, M., et al. (2010) Targeted metagenomics and ecology of globally important uncultured eukaryotic phytoplankton. Proc Natl Acad Sci USA 107: 1467914684.

Gachon, C.M., Sime-Ngando, T., Strittmatter, M., Chambouvet, A., and Kim, G.H. (2010) Algal diseases: spotlight on a black box. Trends Plant Sci 15: 633-640.

Giovannoni, S.J., Delong, E.F., Olsen, G.J., and Pace, N.R. (1988) Phylogenetic group-specific oligodeoxynucleotide probes for identification of single microbial cells. J Bacteriol 170: $720-726$.
Gleason, F.H., and Marano, A.V. (2011) The effects of antifungal substances on some zoosporic fungi (kingdom Fungi). Hydrobiologia 659: 81-92.

Grob, C., Hartmann, M., Zubkov, M.V., and Scanlan, D.J. (2011) Invariable biomass specific primary production of taxonomically discrete picoeukaryote groups across the Atlantic Ocean. Environ Microbiol 12: 3266-3274.

Grob, C., Jardillier, L., Hartmann, M., Ostrowski, M., Zubkov, M.V., and Scanlan, D.J. (2015) Cell-specific CO2 fixation rates of two distinct groups of plastidic protists in the Atlantic Ocean remain unchanged after nutrient addition. Environ Microbiol Rep 7: 211-218.

Guillou, L., Viprey, M., Chambouvet, A., Welsh, R.M., Kirkham, A.R., Massana, R., et al. (2008) Widespread occurrence and genetic diversity of marine parasitoids belonging to Syndiniales (Alveolata). Environ Microbiol 10: 3349-3365.

Hartmann, M., Grob, C., Tarran, G.A., Martin, A.P., Burkill, P.H., Scanlan, D.J., and Zubkov, M.V. (2012) Mixotrophic basis of Atlantic oligotrophic ecosystems. Proc Natl Acad Sci USA 109: 5756-5760.

Hartmann, M., Zubkov, M.V., Scanlan, D.J., and Lepère, C. (2013) In situ interactions between photosynthetic picoeukaryotes and bacterioplankton in the Atlantic Ocean: evidence for mixotrophy. Environ Microbiol Rep 5: 835840.

Jardillier, L., Zubkov, M.V., Pearman, J., and Scanlan, D.J. (2010) Significant $\mathrm{CO}_{2}$ fixation by small prymnesiophytes in the subtropical and tropical northeast Atlantic Ocean. ISME J 4: 1180-1192.

Jebaraj, C.S., Raghukumar, C., Behnke, A., and Stoeck, T. (2010) Fungal diversity in oxygen-depleted regions of the Arabian Sea revealed by targeted environmental sequencing combined with cultivation. FEMS Microbiol Ecol 71: 399-412.

Jobard, M., Rasconi, S., and Sime-Ngando, T. (2010) Diversity and functions of microscopic fungi: a missing component in pelagic food webs. Aquat Sci 72: 255268. 
Jones, M.D.M., Forn, I., Gadelha, C., Egan, M.J., Bass, D., Massana, R., and Richards, T.A. (2011) Discovery of novel intermediate forms redefines the fungal tree of life. Nature 474: 200-203.

Kirkham, A., Lepère, C., Jardillier, L., Mead, A., and Scanlan, D.J. (2013) A global perspective on marine photosynthetic picoeukaryote community structure. ISME J 7: 922-936.

Kohlmeyer, J., and Kohlmeyer, E. (1979) Marine Mycology: The Higher Fungi. New York, USA: Academic Press.

Küpper, F.C., Maier, I., Müller, D.G., Loiseaux-de Goer, S., and Guillou, L. (2006) Phylogenetic affinities of two eukaryotic pathogens of marine macroalgae, Eurychasma dicksonii (Wright) Magnus and Chytridium polysiphoniae Cohn. Cryptogam Algol 27: 165-184.

Lafferty, K.D., Allesina, S., Arim, M., Briggs, C.J., de Leo, G., Dobson, A.P., et al. (2008) Parasites in food webs: the ultimate missing links. Ecol Lett 11: 533-546.

Le Calvez, T., Burgaud, G., Mahé, S., Barbier, G., and Vandenkoornhuyse, P. (2009) Fungal diversity in deep-sea hydrothermal ecosystems. Appl Environ Microbiol 75: 6415-6421.

Leander, B.S., and Keeling, P.J. (2003) Morphostasis in alveolate evolution. Trends Ecol Evol 18: 395-402.

Lepère, C., Domaizon, I., and Debroas, D. (2008) Unexpected importance of potential parasites in the composition of the freshwater small-eukaryote community. Appl Environ Microbiol 74: 2940-2949.

Lepelletier, F., Karpov, S.A., Alacid, E., Le Panse, S., Bigeard, E., Skovgaard, A., et al. (2014) Parvilucifera rostrata sp. nov. (Perkinsozoa), a novel parasitoid that infects planktonic dinoflagellates. Protist 165: 3149.

Liu, H., Probert, I., Uitz, J., Claustre, H., Aris-Brosou, S., Frada, M., et al. (2009) Extreme diversity in non-calcifying haptophytes explains a major pigment paradox in open oceans. Proc Natl Acad Sci USA 106: 12803-12808.

Lopez-Garcia, P., Vereshchaka, A., and Moreira, D. (2007) Eukaryotic diversity associated with carbonates and fluid seawater interface in Lost City hydrothermal field. Environ Microbiol 9: 546-554.

Mangot, J.F., Lepère, C., Bouvier, C., Debroas, D., and Domaizon, I. (2009) Community structure and dynamics of small eukaryotes targeted by new oligonucleotide probes: new insight into the lacustrine microbial food web. Appl Environ Microbiol 75: 6373-6381.

Marcogliese, D.J., and Cone, D.K. (1997) Food webs: a plea for parasites. Trends Ecol Evol 12: 320-325.

Massana, R., and Pedrós-Alió, C. (2008) Unveiling new microbial eukaryotes in the surface ocean. Curr Opin Microbiol 11: 213-218.
Nagahama, T., Hamamoto, M., Nakase, T., Takami, H., and Horikoshi, K. (2001) Distribution and identification of red yeasts in deep-sea environments around the northwest Pacific Ocean. Antonie Van Leeuwenhoek 80: 101110.

Nagano, Y., and Nagahama, T. (2012) Fungal diversity in deep-sea extreme environments. Fungal Ecol 5: 463-471.

Nagano, Y., Nagahama, T., Hatada, Y., Nunoura, T., Takami, H., Miyazaki, J., et al. (2010) Fungal diversity in deep-sea sediments - the presence of novel fungal groups. Fungal Ecol 3: 316-325.

Niquil, N., Kagami, M., Urabe, J., Christaki, U., Viscogliosi, E., and Sime-Ngando, T. (2011) Potential role of fungi in plankton food web functioning and stability: a simulation analysis based on Lake Biwa inverse model. Hydrobiologia 659: 65-79.

Richards, T.A., Jones, M.D.M., Leonard, G., and Bass, D. (2012) Marine fungi: their ecology and molecular diversity. Ann Rev Mar Sci 4: 495-522.

Sauvadet, A.L., Gobet, A., and Guillou, L. (2010) Comparative analysis between protist communities from the deepsea pelagic ecosystems and specific deep hydrothermal habitats. Environ Microbiol 12: 2946-2964.

Siano, R., Alves-de-Souza, C., Foulon, E., El Bendif, M., Simon, N., Guillou, L., and Not, F. (2011) Distribution and host diversity of Amoebophryidae parasites across oligotrophic waters of the Mediterranean Sea. Biogeosciences 8: 267-278.

Sime-Ngando, T., Lefevre, E., and Gleason, F.H. (2011) Hidden diversity among aquatic heterotrophic flagellates: ecological potentials of zoosporic fungi. Hydrobiologia 659: 5-22.

Unrein, F., Gasol, J.M., Not, F., Forn, I., and Massana, R. (2014) Mixotrophic haptophytes are key bacterial grazers in oligotrophic coastal waters. ISME J 8: 164-176.

Vaulot, D., Eikrem, W., Viprey, M., and Moreau, H. (2008) The diversity of small eukaryotic phytoplankton $(<3 \mu \mathrm{m})$ in marine ecosystems. FEMS Microbiol Rev 32: 795-820.

Zhu, F., Massana, R., Not, F., Marie, D., and Vaulot, D. (2005) Mapping of picoeukaryotes in marine ecosystems with quantitative PCR of the 18S rRNA gene. FEMS Microbiol Ecol 52: 79-92.

\section{Supporting information}

Additional Supporting Information may be found in the online version of this article at the publisher's web-site:

Table S1. The location, abundance and composition of PPEs at specific stations along AMT19.

Appendix S1. Materials and methods. 